\title{
Концептуальный анализ стратегического положения бизнес-единиц российской диверсифицированной компании (с использованием матрицы прибыльности Marakon Associates)
}

\author{
Кочугуева М.Н. ${ }^{20}$, Мошкарева Д.А. ${ }^{21}$, Шадрина Н.М. ${ }^{22}$, Юлова С.М. ${ }^{23}$.
}

Целью данного исследования является портфельный анализ стратегического положения бизнес-единиц с использованием матрицы рентабельности Marakon Associates. Данная матрица позволяет рассмотреть положение каждой стратегической бизнесединицы (или дивизиона) с точки зрения трех основных характеристик - рентабельности, роста и возможности генерирования денежных средств. В качестве объекта исследования выступает крупный российский диверсифицированный холдинг - ОАО «Холдинг МРСК» (Межрегиональных распределительных сетевых компаний). В работе нами кратко рассмотрена методология применения матрищь, дано описание компании и отрасли $u$ проведен портфельный анализ положения бизнес-единии ОАО «Холдинг МРСК» за 2009 и 2010 годы.

JEL: $G 110$

Ключевые слова: портфельный анализ, матрица Marakon Associates, диверсифицированная компания, рентабельность, рост, генерирование денежных средств

\section{1. Матрица рентабельности Marakon Associates}

Одной из главных задач менеджмента диверсифицированных компаний является определение конкурентных позиций направлений бизнеса (бизнес-единиц) с целью выявления стратегических альтернатив и создания эффективной системы распределения ресурсов. В решении этой задачи может быть полезен портфельный анализ, основывающийся на системе матриц, разработанных крупными консалтинговыми компаниями во второй половине XX века. Использование портфельного подхода для анализа стратегического положения бизнес-единиц диверсифицированных компаний актуально и по сей день, что в первую очередь связано с простотой и удобством используемого в ходе анализа матричного инструментария.

Применение матриц позволяет наглядно представить стратегическое положение портфеля бизнес-единиц компании как с точки зрения привлекательности отрасли, в которой она функционирует, так и с точки зрения конкурентной позиции бизнеса внутри отрасли. В ходе формулирования основной стратегии бизнеса портфельный анализ помогает сфокусироваться на более узких сегментах и определить роль той или иной бизнес-единицы в общей стратегии компании. Помимо этого на основе позиционирования бизнес-единиц внутри применяемой матрицы можно сделать предположения относительно эффективного распределения ресурсов внутри компании.

Как и любая матрица, применяемая в портфельном анализе, матрица Marakon

\footnotetext{
${ }^{20}$ Канд. эконом. наук, доцент кафедры экономики и финансов фирмы НИУ ВШЭ.

${ }^{21}$ Студентка второго курса магистратуры НИУ ВШЭ по направлению «Стратегическое управление финансами фирмы».

${ }^{22}$ Студентка второго курса магистратуры НИУ ВШЭ по направлению «Стратегическое управление финансами фирмы».

${ }^{23}$ Студентка второго курса магистратуры НИУ ВШЭ по направлению «Стратегическое управление финансами фирмы».
} 
Associates объединяет в себе внешние и внутренние параметры. К внешним относятся потенциал роста рынка или отрасли, а также стоимость собственного капитала компании; к внутренним - возможность генерирования денежных средств и рентабельность собственного капитала. Существует несколько форм представления данной матрицы. Первоначальная форма представлена на рисунке 1. В ней можно выделить семь «домов», каждый из которых характеризуется с позиции трех критериев: рентабельности бизнеса ( $\mathrm{ROE}-\mathrm{Re})$, роста или потери доли в отрасли и с позиции возможности генерирования денежных средств. При этом нужно отметить, что анализ положения бизнес-единиц (далее SBU - strategic business unit) должен проводиться комплексно и учитывать взаимосвязи между данными критериями.

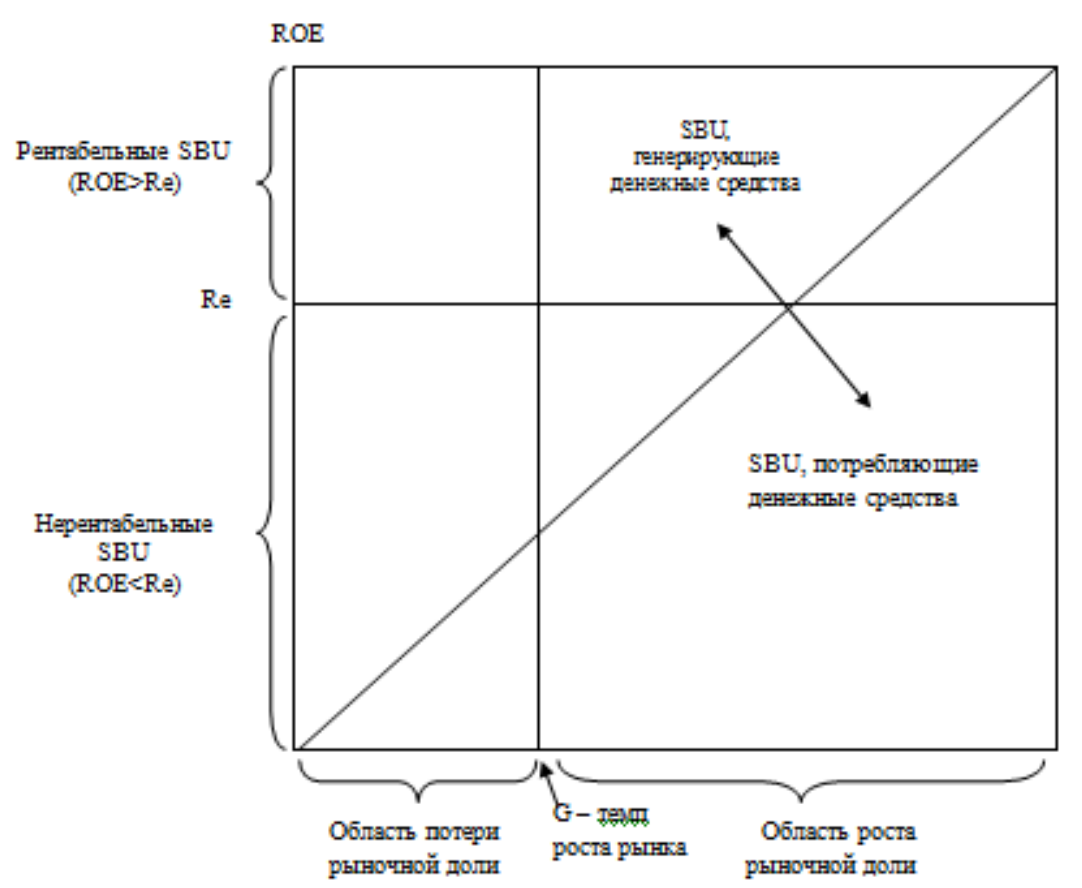

Рисунок 1. Матрица прибыльности Marakon Associates

Применение данной матрицы предполагает нахождение двух критических точек стоимости собственного капитала компании и темпа роста рынка или отрасли. На основе данных показателей можно выделить четыре группы бизнес-единиц:

- рентабельные бизнес-единицы, рентабельность капитала которых превышает требуемую норму доходности собственного капитала;

- нерентабельные бизнес-единицы, рентабельность капитала которых не превышает требуемую норму доходности собственного капитала;

- бизнес-единицы, теряющие рыночную долю (темп роста продаж SBU ниже отраслевого темпа роста);

- бизнес-единицы, наращивающие рыночную долю (темп роста продаж SBU выше отраслевого темпа роста).

Взаимосвязь между рентабельностью собственного капитала и темпом роста компании определяется по формуле:

$$
g=r: \mathbb{R O E}
$$

где:

$$
g_{-} \text {темп роста компании; }
$$

$r$ - коэффициент реинвестирования;

$R O E$ - рентабельность собственного капитала;

$\mathrm{Re}$ - стоимость собственного капитала.

Бизнес-единицы, коэффициент реинвестирования которых равен единице, 
располагаются на диагонали матрицы. Соответственно, в ней можно дополнительно выделить две области, в которых располагаются следующие бизнес-единицы:

- SBU, генерирующие денежные средства, для которых коэффициент реинвестирования меньше единицы;

- SBU, потребляющие денежные средства, для которых коэффициент реинвестирования больше единицы.

Существует также другой способ представления матрицы, где по осям откладывается спред $(\mathrm{ROE}-\mathrm{Re})$ и отношение темпа роста компании к темпу роста отрасли, а критическими точками являются 0 и 1 соответственно. Графически данная матрица представлена на рисунке 2 .

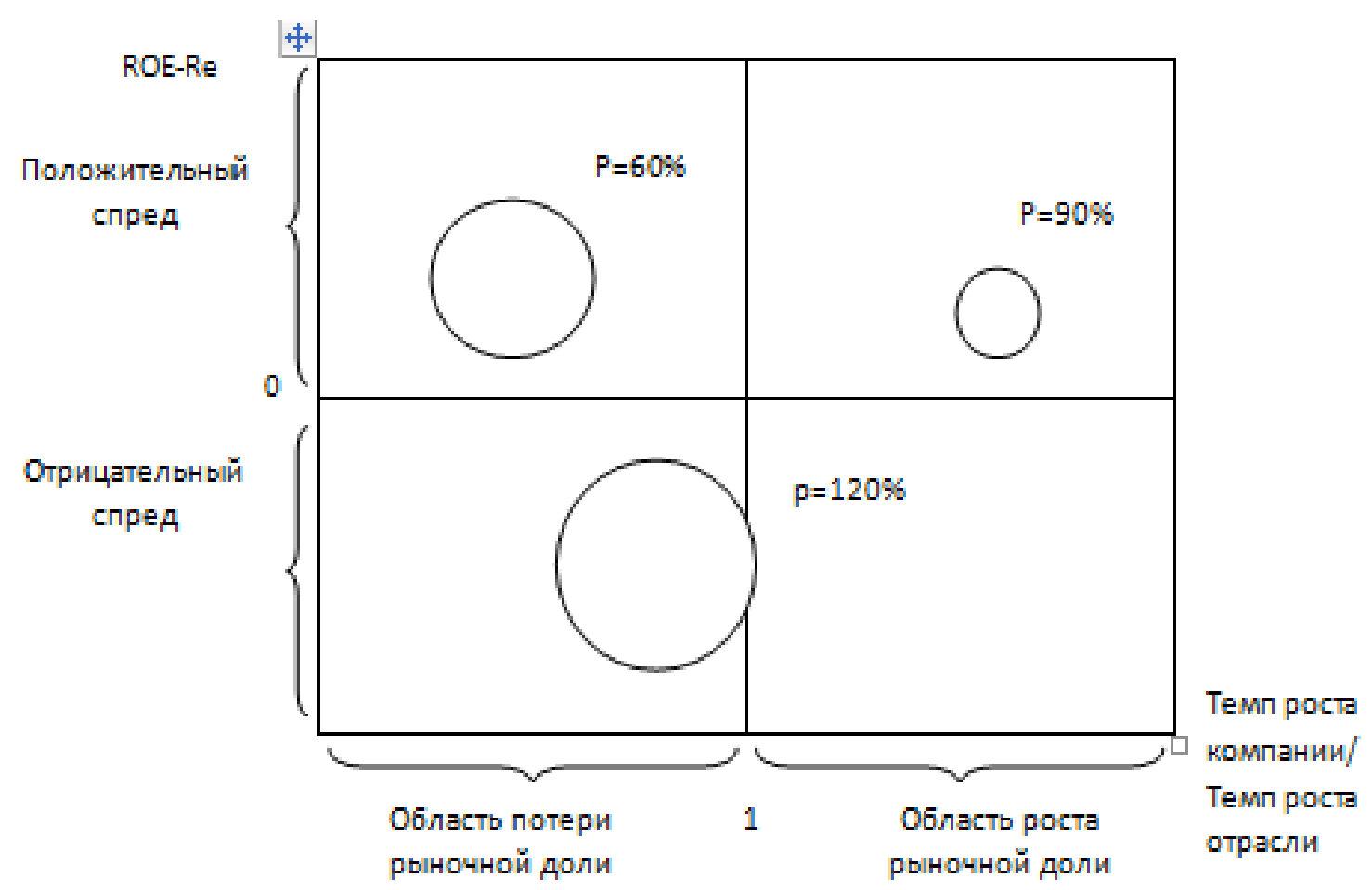

Рисунок 2. Альтернативный способ представления матрицы Marakon Associates

Альтернативный способ представления матрицы позволяет учесть тот факт, что требуемая норма доходности может быть разной для различных бизнес-единиц. Но при этом теряется возможность отражения положения бизнес-единиц с позиции генерирования денежных средств. Коэффициент реинвестирования определяется и подписывается для каждой единицы в отдельности.

Анализ на основе данной матрицы также не является простой задачей и не дает четких ответов относительно возможных альтернатив в отношении бизнес-единиц. Так, Хэкс и Мэжлуф (Наx, Majluf, 2005) в своей работе выделяют три ситуации, когда неблагоприятное положение в матрице не означает категоричного «избавления» от бизнеса:

- молодая компания на стадии роста, которой требуются крупные инвестиции в развитие в настоящем и от которой ожидается высокая рентабельность в будущем;

- издержки выхода из бизнеса превышают издержки, связанные с функционированием компании в настоящем;

- низкорентабельный бизнес, который при этом стратегически важен для компании.

Также авторами отмечается, что анализ данной матрицы должен проводиться комплексно, то есть учитывать динамику и взаимное влияние всех трех критериев в отношении бизнес-единиц.

Что касается применения матричного подхода в целом, то необходимо отметить, что у него имеются свои как сильные, так и слабые стороны. Безусловно, применение матриц - это наиболее простой и удобный способ наглядной оценки бизнес-единиц компании с точки 
зрения их автономной эффективности. Кроме этого, портфельный подход является полезным инструментом, позволяющим оценить стратегические приоритеты компании в целом. Портфельный подход применим не только к своему бизнесу, но и к оценке бизнеса конкурентов, что позволяет оттенить собственную конкурентную позицию.

Очевидны и ограничения портфельного подхода: это, естественно, упрощение фактической ситуации функционирования бизнеса. Поэтому этот удобный и простой инструмент должен быть дополнен другими видами анализа.

\section{2. Анализ портфеля компаний ОАО «Холдинг МРСК» на основе матрицы рентабельности Marakon Associates}

ОАО «Холдинг МРСК» было образовано в конце 2007 года в ходе реструктуризации ОАО РАО «ЕЭС России». В результате реструктуризации все распределительные сетевые компании были объединены в холдинг, образовав, таким образом, монополию на рынке распределительных сетей среднего и низкого напряжения. Сегодня МРСК представляет собой одну из крупнейших сетевых компаний в мире по показателям объемов передачи электроэнергии, протяженности сетей и величине активов.

На сегодняшний день отрасль электроэнергетики России находится в процессе реформирования, в том числе и отрасль распределительных сетей. До недавнего времени тарифы на услуги распределительных компаний фиксировались по системе «затраты плюс», что не только снижало эффективность их функционирования, но и не стимулировало компании к росту и развитию (улучшению показателей деятельности). Начиная с 2009 года отдельные компании в структуре холдинга начали переход на новую тарифную систему $\mathrm{RAB}-$ регулирование, которое предполагает долгосрочную систему регулирования тарифов, направленную на привлечение инвестиций в модернизацию сетевой инфраструктуры компаний. Данная система стимулирует компании к сокращению издержек, так как оставшиеся средства остаются в распоряжении самих компаний. При этом система предполагает возврат вложенных инвестиций, в том числе и процентов на привлеченный капитал, что по характеристикам приближает инвестиции в распределительные компании к инвестициям в инструменты с фиксированной доходностью.

Для того чтобы осуществить портфельный анализ на основе матрицы Marakon Associates, в первую очередь необходимо выделить стратегические бизнес-единицы компании. В собственности ОАО «Холдинг МРСК» по состоянию на 31 декабря 2010 года находились контрольные пакеты акций 44 компаний, деятельность которых можно распределить по пяти основным направлениям. Характеристика основных направлений деятельности компании представлена в таблице 1.

Таблица 1

Выделение основных направлений деятельности компании

\begin{tabular}{|c|c|}
\hline & Характеристика направлений \\
\hline МРСК & $\begin{array}{l}11 \text { межрегиональных распределительных сетевых компаний (МРСК) - } \\
\text { специализированные сетевые организации, основной вид деятельности } \\
\text { которых заключается в оказании услуг по передаче электроэнергии от } \\
\text { генерирующих компаний через собственные электрические сети конечным } \\
\text { потребителям. В основе образования МРСК заложен принцип } \\
\text { территориальной сопряженности и сопоставимости стоимости входящих в } \\
\text { состав МРСК активов распределительных сетевых компаний }\end{array}$ \\
\hline РCK & $\begin{array}{l}\text { Помимо акций МРСК, холдинг владеет акциями пяти распределительных } \\
\text { сетевых компаний (РСК), которые пока не относятся ни к одной из МРСК. } \\
\text { Деятельность РСК также направлена на обеспечение потребителей } \\
\text { электрической энергией, однако РСК отличаются от МРСК как стоимостью } \\
\text { активов, так и величиной генерируемой выручки }\end{array}$ \\
\hline
\end{tabular}




\begin{tabular}{|l|l|}
\hline $\mathbf{C Д}$ & $\begin{array}{l}\text { Деятельность семи сбытовых компаний заключается в оптимизации издержек } \\
\text { сбытовой деятельности, улучшении организации сбытовой деятельности на } \\
\text { розничном рынке }\end{array}$ \\
\hline $\mathbf{H T}$ & $\begin{array}{l}\text { номпаний научно-исследовательского профиля занимаются созданием } \\
\text { новых технологий в области производства, транспорта и распределения } \\
\text { электроэнергии }\end{array}$ \\
\hline $\mathbf{C C O}$ & $\begin{array}{l}13 \text { строительных, снабженческих и обслуживающих компаний - сдача в } \\
\text { аренду помещений, движимого имущества, объектов непромышленной сферы } \\
\text { и т.д. }\end{array}$ \\
\hline
\end{tabular}

На следующем этапе нами были рассчитаны рентабельность собственного капитала, а также темпы роста продаж для каждой бизнес-единицы, требуемая норма доходности собственного капитала для ОАО «Холдинг МРСК» и темп роста отрасли электроэнергетики.

Темп роста рынка рассчитывался на основе темпа роста индекса «ММВБ-Энергетика» за соответствующий год из предположения, что на 25\% этот рост обеспечен ростом рынка распределительных сетевых компаний ${ }^{24}$. В связи с тем что рассматриваемая компания является монополистом на рынке распределительных сетей, в качестве темпа роста отрасли можно было бы использовать темп роста выручки холдинга. Однако, на наш взгляд, в связи с отсутствием до недавнего времени рыночных стимулов функционирования компаний в данном секторе такую прокси-переменную для темпа роста рынка нельзя считать обоснованной.

Расчет стоимости собственного капитала компании проводился на основе национальной модели САРМ с учетом странового риска.

$$
R e=R f+\beta=E R P+\text { Courtry spread, }
$$

где:

$R e$ - требуемая доходность собственного капитала компании;

$R f$ - доходность безрискового актива;

$B$ - бета-коэффициент, характеризующий степень риска компании относительно рынка в целом;

$E R P$ - рыночная риск-премия;

Country spread - страновой риск.

В качестве доходности безрискового актива принималась доходность по российским государственным облигациям. Расчет требуемой нормы доходности собственного капитала МРСК и основные источники данных представлены в таблице 2.

Итоговые значения рентабельности собственного капитала и темпа роста для каждой бизнес-единицы были получены путем взвешивания по долям выручки компании относительно общей выручки стратегической бизнес-единицы. Результаты расчетов показателей для построения матрицы прибыльности представлены в таблицах 3 и 4.

Таблица 2

Расчет требуемой нормы доходности собственного капитала

ОАО «Холдинг МРСК»

\begin{tabular}{|l|l|l|l|}
\hline \multicolumn{1}{|c|}{ Показатель } & \multicolumn{1}{c|}{ Источник информации } & \multicolumn{1}{c|}{$\mathbf{2 0 0 9}$ г. } & $\mathbf{2 0 1 0}$ г. \\
\hline Risk-free rate, \% & International Financial Statistics & 8,75 & 7,57 \\
\hline Equity Risk Premium, \% & Damodaran & 6,90 & 7,25 \\
\hline Beta & Bloomberg & 1 & 1 \\
\hline Country Spread, \% & Damodaran & 2,40 & 2,25 \\
\hline Re & & $\mathbf{1 8 , 0 5}$ & $\mathbf{1 7 , 0 7}$ \\
\hline
\end{tabular}

\footnotetext{
${ }^{24}$ Данное предположение было высказано менеджментом компании в соответствующем годовом отчете.
} 
Таблица 3

Показатели прибыльности и темпа роста по направлениям деятельности

\begin{tabular}{|c|c|c|c|c|c|}
\hline \multicolumn{6}{|c|}{ в 2009 году } \\
\hline Показатели & МРСК & РСК & СД & HT & $\mathrm{CCO}$ \\
\hline ROE, \% & 2,17 & $-11,63$ & $-5,78$ & 27,85 & 39,15 \\
\hline Spread (ROE-Re), \% & $-15,88$ & $-29,68$ & $-23,83$ & 9,80 & 21,10 \\
\hline Growth rate $(\mathrm{g}), \%$ & 36,49 & 13,88 & 20,12 & 46,07 & 8,81 \\
\hline $\mathrm{g} / \mathrm{G}$ & 0,87 & 0,33 & 0,48 & 1,10 & 0,21 \\
\hline Reinvestment rate ( r) & 16,81 & $-1,19$ & $-3,48$ & 1,65 & 0,23 \\
\hline Industry growth rate $(G), \%$ & 42,00 & & & & \\
\hline Cost of equity, $\%$ & 18,05 & & & & \\
\hline
\end{tabular}

Таблица 4

Показатели прибыльности и темпа роста по направлениям деятельности

в 2010 году

\begin{tabular}{|c|c|c|c|c|c|}
\hline Показатели & МРСК & РСК & СД & HT & $\mathrm{CCO}$ \\
\hline ROE, \% & 4,48 & $-11,39$ & 25,46 & 20,76 & 20,48 \\
\hline Spread (ROE-Re), \% & $-12,59$ & $-28,46$ & 8,39 & 3,69 & 3,41 \\
\hline Growth rate (g), \% & 22,23 & 22,01 & 14,60 & 5,23 & 27,27 \\
\hline$g / G$ & 2,02 & 2,00 & 1,33 & 0,48 & 2,48 \\
\hline Reinvestment rate ( $r$ ) & 4,97 & $-1,93$ & 0,57 & 0,25 & 1,33 \\
\hline Industry growth rate $(\mathrm{G}), \%$ & 11,00 & & & & \\
\hline Cost of equity, \% & 17,07 & & & & \\
\hline
\end{tabular}

В 2009 году доходность собственного капитала выше, чем значение требуемой доходности, показывают такие непрофильные бизнес-единицы, как научноисследовательские (НТ), строительные, снабженческие и обслуживающие компании (ССО). Доходность собственного капитала - на уровне 28 и 39\% соответственно, однако темп роста ССО $(8,81 \%)$ ниже отраслевого (42\%). Основные направления бизнеса (РСК и СД) оказались нерентабельными, и темп их роста был ниже отраслевого, хотя рентабельность собственного капитала распределительных компаний (МРСК) положительная, она не превышает требуемую доходность собственного капитала. 


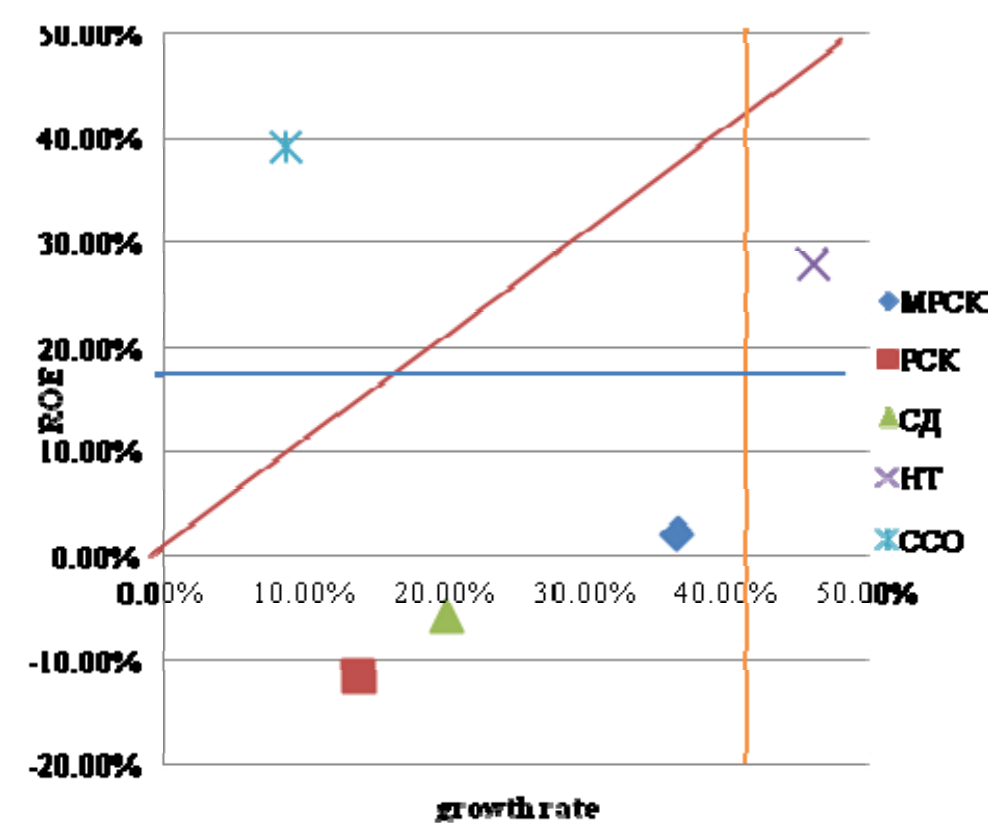

Рисунок 3. Матрица прибыльности по направлениям деятельности в 2009 году

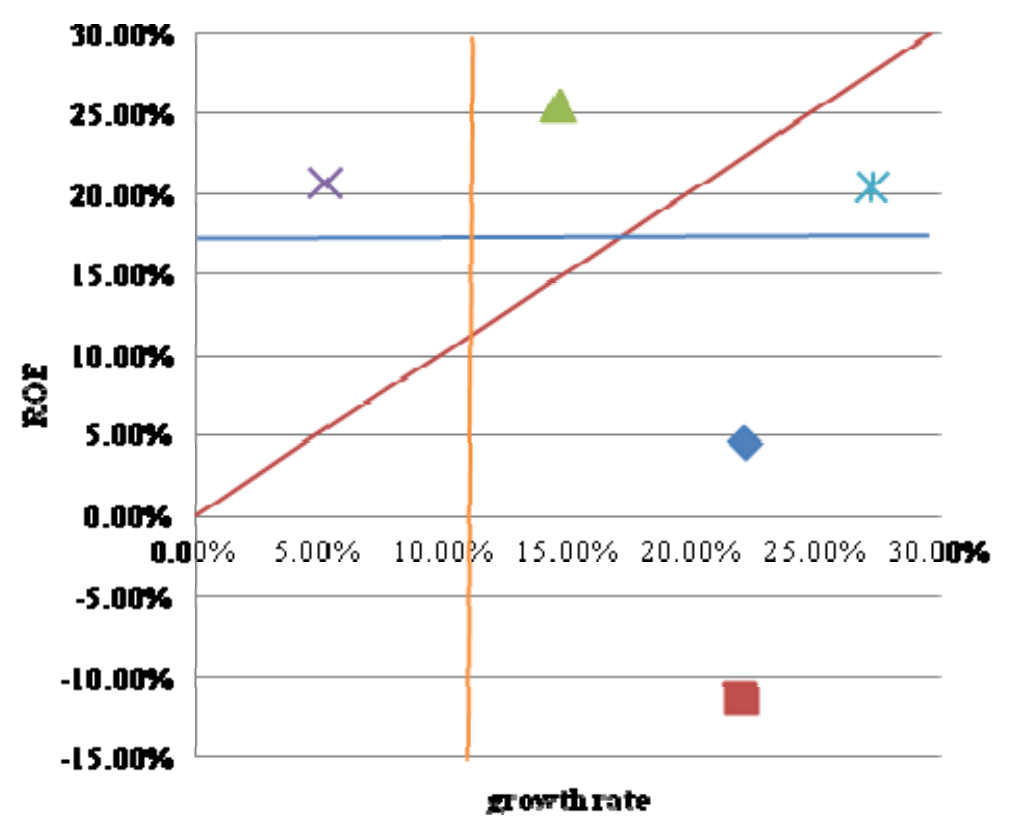

Рисунок 4. Матрица прибыльности по направлениям деятельности в 2010 году

Однако нужно отметить, что в целом для 2009 года характерно восстановление рынка, поэтому темпы роста отрасли были очень высокими. В 2010 произошло снижение темпа роста отрасли с 42 до 11\%. В результате такого снижения, все направления, кроме строительных, обслуживающих и снабженческих компаний (CCO), имеют более высокие темпы роста по сравнению с отраслью. Темпы роста основных направлений бизнеса распределительных компаний - показывают разнонаправленную динамику, но в среднем составляют 22\%. Также нужно отметить положительную динамику рентабельности МРСК, которая достигла 5\%-ного уровня, но при этом остается значительно ниже требуемой доходности.

При построении «модифицированной» матрицы прибыльности был учтен размер генерируемой выручки в рамках каждого направления: чем больше выручка, тем больше площадь круга. Результаты за 2009 и 2010 годы представлены на следующих рисунках. 


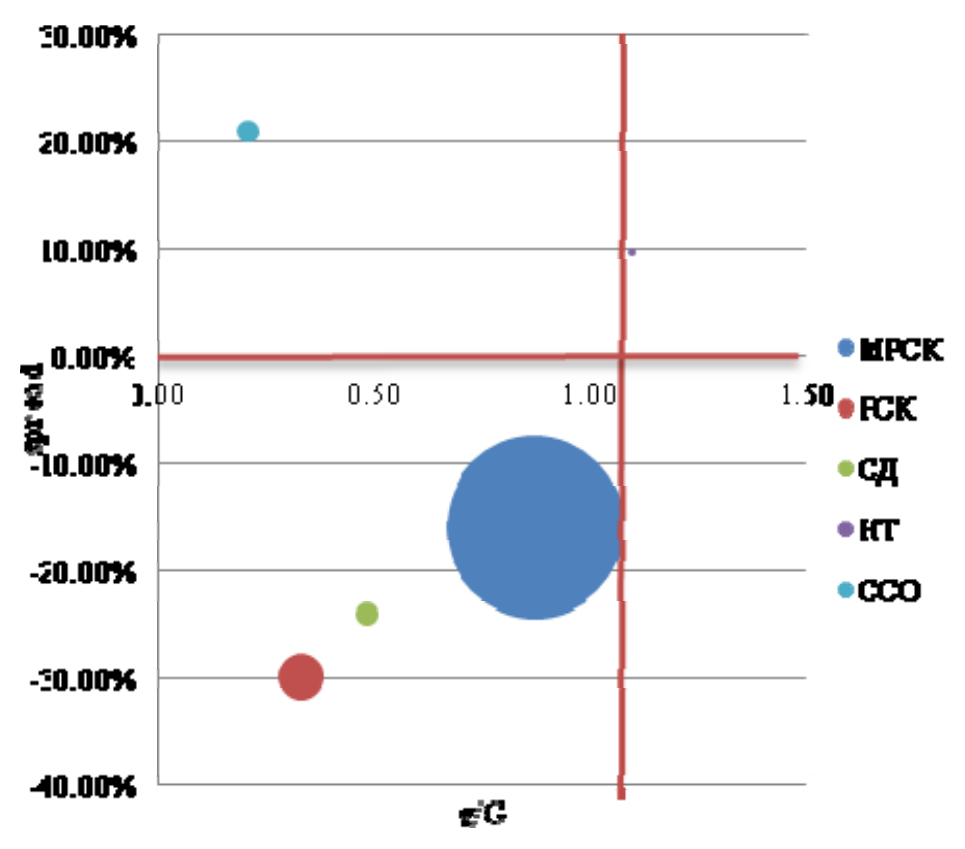

Рисунок 5. Модифицированная матрица прибыльности по направлениям деятельности в 2009 году

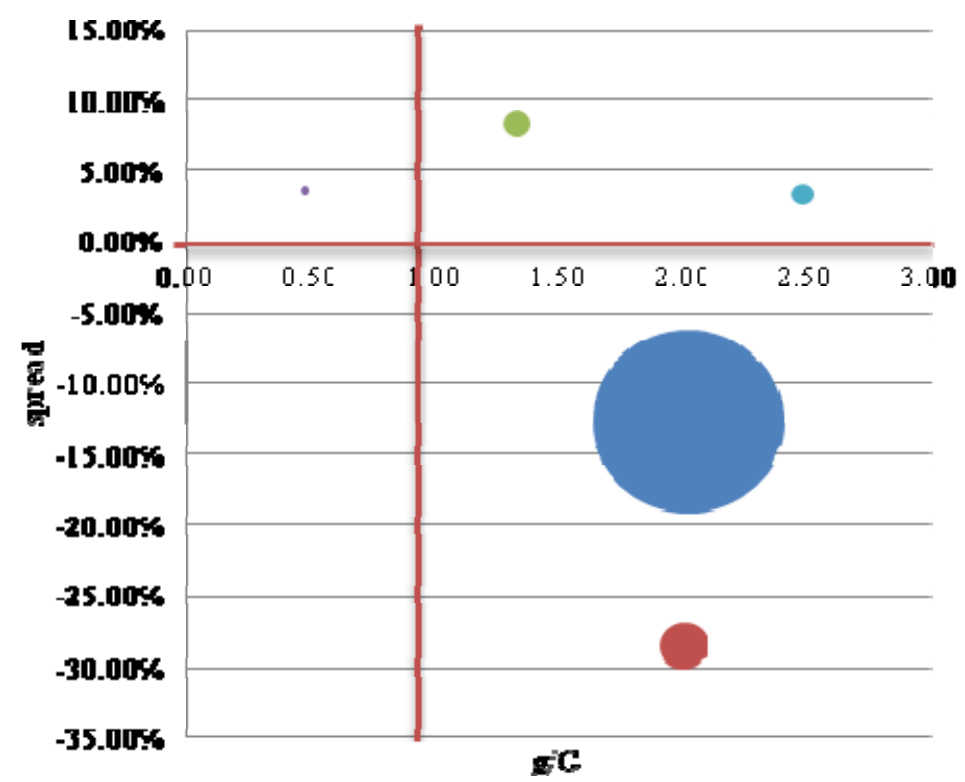

Рисунок 6. Модифицированная матрица прибыльности по направлениям деятельности в 2010 году

Как мы видим, основную долю выручки ОАО «Холдинг МРСК» генерируют межрегиональные сетевые распределительные компании, однако при этом они скорее являются потребителями денежных средств - коэффициент реинвестирования для этого направления превышает единицу. Положительные потоки денежных средств генерируются направлениями СД и НТ, доля которых в общем объеме выручки является наименьшей, что является одним из факторов неэффективности портфеля ОАО «Холдинг МРСК». С другой стороны, стратегически важное для компании направление МРСК, которое генерирует основной объем выручки и обеспечивает достаточно высокий темп роста, имеет низкое значение рентабельности собственного капитала. Для того чтобы выяснить причины такого несоответствия, проведем аналогичный портфельный анализ внутри данного направления.

Для того чтобы построить матрицу Marakon Associates, нам необходимо выделить 
бизнес-единицы. Традиционным для отрасли распределительных сетей является деление по региональному признаку. Направление МРСК объединяет в себе 11 сетевых компаний: ОАО «МРСК Центра», ОАО «МРСК Урала», ОАО «Ленэнерго», ОАО «МОЭСК», ОАО «Тюменьэнерго», ОАО «МРСК Волги», ОАО «МРСК Сибири», ОАО «МРСК Центра и Приволожья», ОАО «МРСК Северо-Запада», ОАО «МРСК Северного Кавказа», ОАО «МРСК Юга».

Операционная деятельность всех бизнес-единиц ориентирована исключительно на внутренний рынок и характеризуется полным отсутствием конкуренции. Все компании приблизительно сопоставимы между собой по операционным и финансовым показателям, однако имеют серьезные различия по географическому местоположению, структуре активов, количеству филиалов, норме потерь, размеру тарифа на передачу, объему инвестиционных программ и планам по техническому присоединению. Помимо этого, компании имеют разное финансовое состояние и уровень долговой нагрузки.

Чтобы определить экономический вклад каждой компании в развитие направления МРСК и выявить, за счет каких компаний эффективность деятельности направления МРСК растет, а за счет каких - снижается, была построена матрица рентабельности по данной группе. Для построения матрицы были рассчитаны необходимые показатели для каждой бизнес-единицы в 2009 и 2010 годах, значения которых представлены в таблицах 5 и 6.

Таблица 5

Показатели прибыльности и темпа роста по бизнес-единицам в рамках направления МРСК в 2009 году

\begin{tabular}{|c|c|c|c|c|c|c|c|c|c|c|c|}
\hline $\begin{array}{c}\text { Показат } \\
\text { ели }\end{array}$ & $\begin{array}{c}\text { МОЭС } \\
\text { К }\end{array}$ & $\begin{array}{c}\text { МРC } \\
\text { К } \\
\text { Цент } \\
\text { pa }\end{array}$ & $\begin{array}{c}\text { МРСК } \\
\text { Север } \\
\text { о- } \\
\text { Запада }\end{array}$ & $\begin{array}{c}\text { МРС } \\
\text { К } \\
\text { Урал } \\
\mathbf{a}\end{array}$ & $\begin{array}{c}\text { МРС } \\
\text { К } \\
\text { Сиби } \\
\text { ри }\end{array}$ & $\begin{array}{c}\text { МРСК } \\
\text { Центра } \\
\text { и } \\
\text { Привол } \\
\text { жья } \\
\end{array}$ & $\begin{array}{c}\text { МРС } \\
\text { К } \\
\text { Волг } \\
\text { и }\end{array}$ & $\begin{array}{c}\text { MPC } \\
\text { К } \\
\text { Юга }\end{array}$ & $\begin{array}{c}\text { МРСК } \\
\text { Север } \\
\text { ного } \\
\text { Кавка } \\
\text { за } \\
\end{array}$ & $\begin{array}{c}\text { Лен- } \\
\text { энерг } \\
\text { о }\end{array}$ & $\begin{array}{c}\text { Tюмен } \\
\text { ь- } \\
\text { энерго }\end{array}$ \\
\hline ROE, \% & 5,42 & 3,27 & 0,54 & 3,81 & $-2,39$ & 1,06 & 0,35 & $-5,35$ & $-3,74$ & 6,72 & 2,53 \\
\hline $\begin{array}{l}\text { Spread } \\
\text { (ROE- } \\
\text { Re) \% }\end{array}$ & $-12,63$ & $\begin{array}{l}- \\
14,78\end{array}$ & $-17,51$ & $-14,24$ & $\overline{20,44}$ & $-16,99$ & $\begin{array}{l}- \\
17,70\end{array}$ & $\overline{23,40}$ & $-21,79$ & $-\overline{11,33}$ & $-15,52$ \\
\hline $\begin{array}{l}\text { Growth } \\
\text { rate }(\mathrm{g}) \text {, } \\
\%\end{array}$ & 35,26 & 37,56 & 56,35 & 73,68 & 5,92 & 48,93 & 29,64 & 44,95 & 49,42 & 25,26 & 5,83 \\
\hline$g / G$ & 0,84 & 0,89 & 1,34 & 1,75 & 0,14 & 1,17 & 0,71 & 1,07 & 1,18 & 0,60 & 0,14 \\
\hline $\begin{array}{l}\text { Reinvest } \\
\text { ment } \\
\text { rate ( } r)\end{array}$ & 6,50 & 11,50 & 105,22 & 19,34 & $-2,48$ & 46,11 & 85,60 & $-8,41$ & $-13,22$ & 3,76 & 2,30 \\
\hline $\begin{array}{l}\text { Industry } \\
\text { growth } \\
\text { rate (G), } \\
\% \\
\end{array}$ & 42,00 & & & & & & & & & & \\
\hline $\begin{array}{l}\text { Cost of } \\
\text { equity, } \\
\%\end{array}$ & 18,05 & & & & & & & & & & \\
\hline
\end{tabular}


Показатели прибыльности и темпа роста по бизнес-единицам в рамках направления МРСК в 2010 году

\begin{tabular}{|c|c|c|c|c|c|c|c|c|c|c|c|}
\hline $\begin{array}{c}\text { Показат } \\
\text { ели }\end{array}$ & $\begin{array}{c}\text { МОЭС } \\
\text { К }\end{array}$ & $\begin{array}{c}\text { МРC } \\
\text { К } \\
\text { Цент } \\
\text { pa }\end{array}$ & $\begin{array}{c}\text { МРСК } \\
\text { Север } \\
\text { о- } \\
\text { Запада }\end{array}$ & $\begin{array}{c}\text { МРC } \\
\text { К } \\
\text { Урал } \\
\mathbf{a}\end{array}$ & $\begin{array}{c}\text { МРС } \\
\text { К } \\
\text { Сиби } \\
\text { ри }\end{array}$ & $\begin{array}{c}\text { МРСК } \\
\text { Центра } \\
\text { и } \\
\text { Привол } \\
\text { жья } \\
\end{array}$ & $\begin{array}{c}\text { МРС } \\
\text { К } \\
\text { Волг } \\
\text { и }\end{array}$ & $\begin{array}{c}\text { МРC } \\
\text { К } \\
\text { Юга }\end{array}$ & $\begin{array}{c}\text { МРСК } \\
\text { Север } \\
\text { ного } \\
\text { Кавка } \\
\text { за } \\
\end{array}$ & $\begin{array}{c}\text { Лен- } \\
\text { энер } \\
\text { го }\end{array}$ & $\begin{array}{r}\text { Тюмен } \\
\text { ьэнерго }\end{array}$ \\
\hline ROE, \% & 12,27 & 10,81 & $-2,91$ & 5,81 & $-9,24$ & 3,40 & 0,64 & $\overline{19,52}$ & 3,97 & 7,60 & 7,13 \\
\hline $\begin{array}{l}\text { Spread } \\
\text { (ROE- } \\
\text { Re), \% }\end{array}$ & $-4,79$ & $-6,26$ & $-19,98$ & - & - & $-13,67$ & $\begin{array}{l}- \\
16,43\end{array}$ & $\begin{array}{l}- \\
36,58\end{array}$ & $-13,09$ & $-9,46$ & $-9,94$ \\
\hline $\begin{array}{l}\text { Growth } \\
\text { rate }(\mathrm{g}) \text {, } \\
\%\end{array}$ & 29,80 & 23,14 & 6,50 & 20,55 & 9,71 & 15,27 & 34,46 & 15,70 & 4,82 & 31,10 & 23,90 \\
\hline$g / G$ & 2,71 & 2,10 & 0,59 & 1,87 & 0,88 & 1,39 & 3,13 & 1,43 & 0,44 & 2,83 & 2,17 \\
\hline $\begin{array}{l}\text { Reinvest } \\
\text { ment } \\
\text { rate }(r)\end{array}$ & 2,43 & 2,14 & $-2,24$ & 3,54 & $-1,05$ & 4,49 & 53,99 & $-0,80$ & 1,21 & 4,09 & 3,35 \\
\hline $\begin{array}{l}\text { Industry } \\
\text { growth } \\
\text { rate (G), } \\
\%\end{array}$ & 11,00 & & & & & & & & & & \\
\hline $\begin{array}{l}\text { Cost of } \\
\text { equity, } \\
\%\end{array}$ & 17,07 & & & & & & & & & & \\
\hline
\end{tabular}

В первую очередь отметим, что все компании как в 2009, так и в 2010 году являлись потребителями денежных средств. В 2009 году все бизнес-единицы находились в зоне прибыльности ниже по отношению к затратам на собственный капитал. Есть и такие компании, значение ROE которых отрицательно. ОАО «МОЭСК» и ОАО «МРСК Центра» демонстрируют значительный рост прибыльности в 2010 году по сравнению с 2009, значение ROE выросло с 5,42 до 12,27\% и с 3,27 до 10,81\% соответственно.

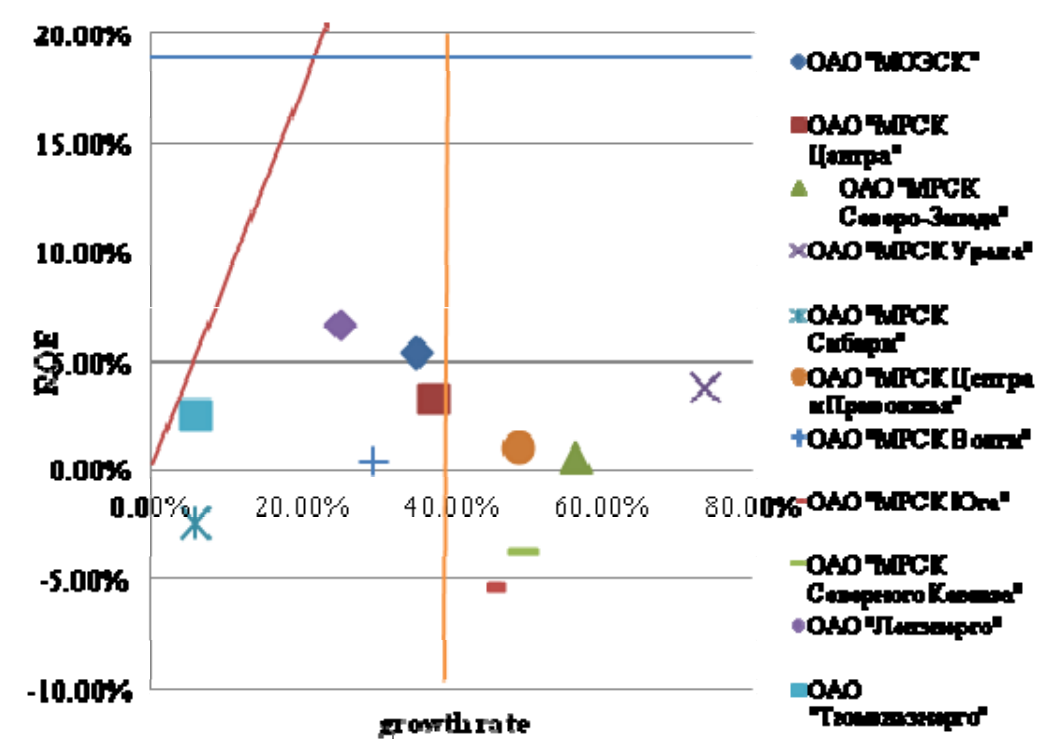

Рисунок 6. Матрица прибыльности по бизнес-единицам в рамках направления МРСК в 2009 году 


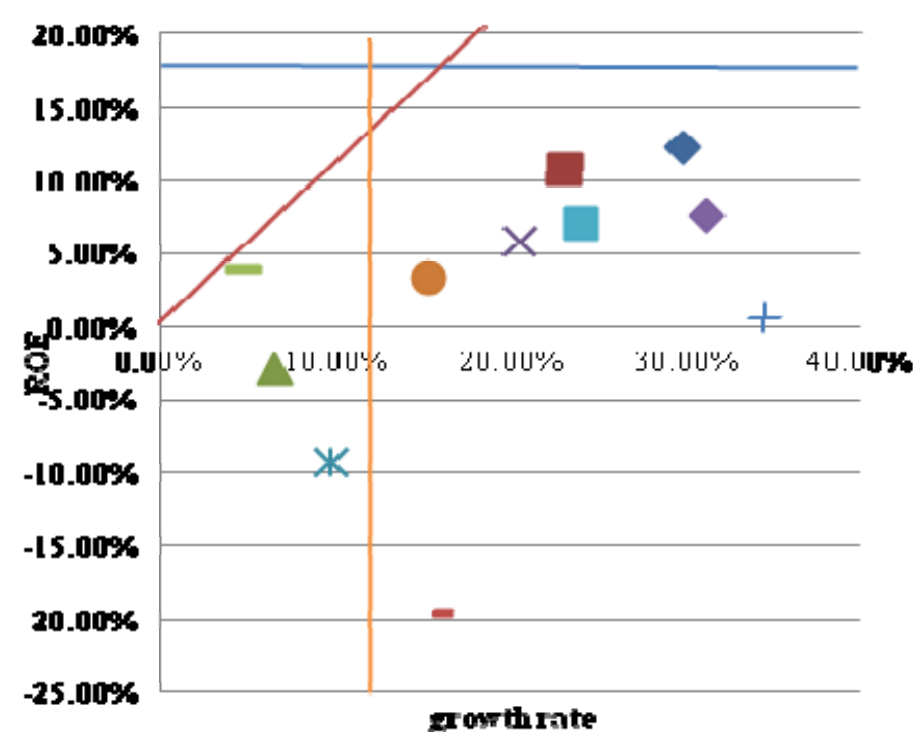

Рисунок 7. Матрица прибыльности по бизнес-единицам в рамках направления МРСК в 2009 году

На наш взгляд, основным фактором, объясняющим увеличение доходности компаний, является переход на новый метод регулирования тарифов - RAB-регулирование, при котором уровень эффективности каждой бизнес единицы может быть определен степенью внедрения новой системы тарифов в компании. Например, в 2010 году доходность ОАО «МРСК Центра» значительно выросла по сравнению с 2009 годом, так как большая часть филиалов ОАО «МРСК Центра» уже перешли на RAB-регулирование.

Что касается темпа роста компаний, то ситуация в 2010 году изменилась по сравнению с 2009 годом. В 2009 году только у пяти компаний из 11 (ОАО «МРСК Северо-Запада», ОАО «МРСК Центра и Приволжья», ОАО «МРСК Урала», ОАО «МРСК Северного Кавказа», ОАО «МРСК Юга») темпы роста были выше отраслевого. В 2010 году большинство компаний продемонстрировали хороший рост и поэтому переместились в зону с темпом роста больше отраслевого.
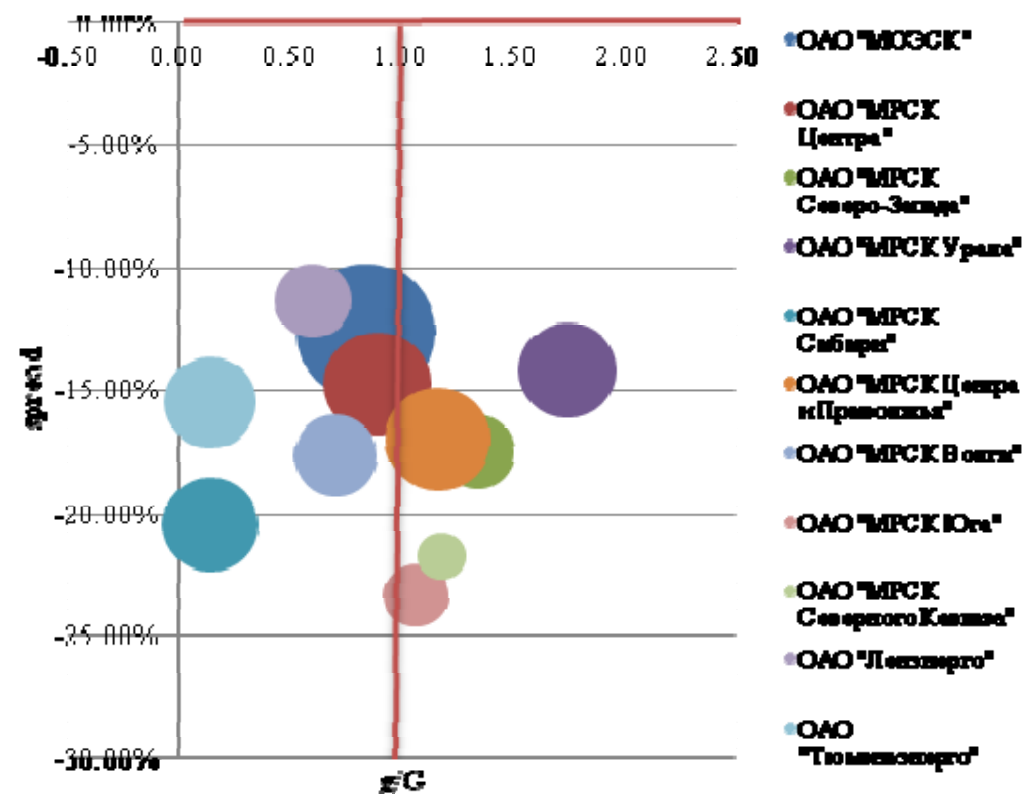

Рисунок 8. Модифицированная матрица прибыльности по бизнес-единицам в рамках направления SBU1 в 2009 году 


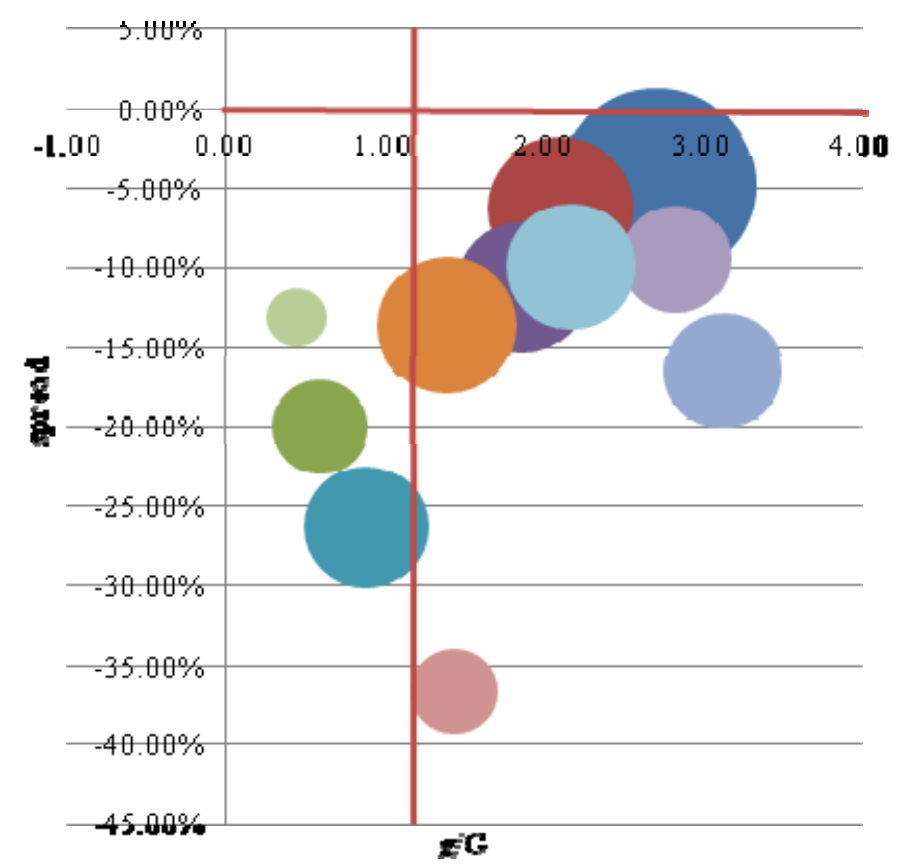

Рисунок 9. Модифицированная матрица прибыльности по бизнес-единицам в рамках направления SBU1 в 2010 году

Для определения положения бизнес-единиц относительно рынка и с учетом доли каждой компании в выручке всего направления были построены матрицы модифицированного вида за 2009 и 2010 годы.

Таким образом, применение матрицы рентабельности Marakon Associates для портфеля бизнес-единиц ОАО «Холдинг МРСК» показало в целом неэффективность функционирования распределительных сетевых компаний. Наилучшие позиции как с точки зрения роста, так и с точки зрения рентабельности бизнеса занимают такие непрофильные виды деятельности, как научно-исследовательские, а также строительные и снабженческие работы. Однако, несмотря на положительный денежный поток, генерируемый данными направлениями, этих средств явно не хватит для поддержания эффективного функционирования основного направления деятельности - распределительных сетей.

Практически все распределительные компании характеризуются неэффективностью деятельности с точки зрения рентабельности собственного капитала: несмотря на рост, ROE не превышает требуемую норму доходности собственного капитала компании. При этом все компании в рамках направления МРСК являются потребителями денежных средств, что связано с наличием крупномасштабных инвестиционных программ. Решением таких серьезных несоответствий должно стать введение новой системы RAB-регулирования. K тому же, как показал анализ, применение матрицы рентабельности позволяет уловить переход некоторых компаний на новую, более эффективную систему.

Однако, с другой стороны, применение матриц не позволяет сделать однозначного вывода о возможной реструктуризации портфеля, что связано с несколькими факторами. В первую очередь, отсутствие конкуренции на рынке распределительных сетевых компаний не позволяет говорить о рыночной эффективности функционирования данных компаний. С другой стороны, сегодня далеко не все компании исследуемой отрасли перешли на новую систему формирования тарифов, что затрудняет проведение адекватного сравнительного анализа бизнес-единиц внутри портфеля. Поэтому, на наш взгляд, портфельный анализ ОАО «Холдинг МРСК» может дать более адекватные результаты после полного перехода компаний на RAB-регулирование. 


\section{Список литературы}

1. Катькало В.С. Исходные концепции стратегического управления и их современная оценка // Российский журнал менеджмента. 2003. № 1.

2. Шанк Дж., Говиндараджан В. Стратегическое управление затратами: Новые методы увеличения конкурентоспособности. СПб.: Бизнес Микро, 1999.

3. ОАО «Холдинг МРСК»: официальный сайт. URL: http://www.holding-mrsk.ru.

4. ОАО «МОЭСК»: официальный сайт. URL: http://www.moesk.ru.

5. ОАО «МРСК Центра»: официальный сайт. URL: http://www.mrsk-1.ru.

6. ОАО «МРСК Северо-Запада»: официальный сайт. URL: http://www.mrsksevzap.ru

7. ОАО «МРСК Урала»: официальный сайт. URL: http://www.mrsk-ural.ru.

8. ОАО «МРСК Сибири»: официальный сайт.URL: http://www.mrsk-sib.ru.

9. ОАО «ОАО «Тюменьэнерго»: официальный сайт. URL: http://www.te.ru.

10. OAО «Ленэнерго»: официальный сайт. URL: http://www.lenenergo.ru.

11. OAО «МРСК Северного Кавказа»: официальный сайт. URL: http://www.mrsk-sk.ru.

12. ОАО «МРСК Юга»: официальный сайт. URL: http://www.mrsk-yuga.ru.

13. ОАО «МРСК Волги»: официальный сайт. URL: http://www.mrsk-volgi.ru.

14. OAO «МРСК Центра и Приволжья»: официальный сайт. URL: http://www.mrsk-cp.ru.

15. Damodaran Online: Home page for Aswath Damodaran (2010). URL: www.damodaran.com.

16. Hax A.C., Majluf N.S. (2005), The Strategy Concept and Process: A Pragmatic Approach. London Prentice-Hall International, Inc. 